\title{
MODIFIED TRIPLE ASSESSMENT IN BREAST LUMPS
}

\author{
Karunamoorthy Rajachidambaram1, Tumkur Kumar Sowmya²
}

${ }^{1}$ Associate Professor, Department of General Surgery, Chennai Medical College Hospital and Research Centre, Irungalur, Trichy. ${ }^{2}$ Assistant Professor, Department of General Surgery, Chennai Medical College Hospital and Research Centre, Irungalur, Trichy.

\section{ABSTRACT}

\section{OBJECTIVES}

The advances in modern surgery era for assessment of breast lumps has not replaced the triple assessment, which are clinical examination, radiological examination and pathological examination.(1) This study is about to substitute mammogram and ultrasonogram to assess the palpable breast lumps.(2) combined with other two modalities.

\section{METHODS}

Place of Study

Department of General Surgery, Chennai Medical College Hospital, Irungalur, Trichy.

Method of collection of data: A prospective cross sectional study of 100 female patients with palpable breast lumps attending outpatient department was done and study period is from April 2013 to September 2015.

\section{Inclusion Criteria}

Females more than 30 yrs. Females presenting with palpable breast lump.

\section{Exclusion Criteria}

Female patient less than 30 yrs. Male patients. Advanced breast cancer patients.

\section{RESULTS}

Out of 100 female patients, 68 patients with 73 breast lumps were inducted into the study. The MTT obviated excision biopsy in 16 patients $(22 \%)$ and this is the potential advantage of this test. Thus the final study group $\left(\mathrm{n}^{\wedge} 57\right)$ underwent the MTT followed by excision biopsy, the results of which were available for comparison. The average age of women in this study was $41.84+9.1$. The mean shifting to 47 years in patients with malignancy, the youngest patient was 30 years and the oldest was 65 years. This conforms with the suitable age for subjecting patients to screening procedure followed worldwide (i.e.) above 40 years; 9 women were nulliparous of which only 3 had malignant lesions. The rest (n-48) were nulliparous. The results do not point to any positive association between parity and malignancy $(\mathrm{P}>0.05)$.

\section{CONCLUSION}

We conclude that modified triple assessment is a very useful diagnostic tool to evaluate patients with breast lumps and to detect patients with breast cancers with replacing core needle biopsy instead FNAC and Ultrasonogram for Mammogram pertaining to facility available.

\section{KEYWORDS}

Clinical Examination, Mammography, Ultrasonography, Fine-needle Aspiration Cytology, Carcinoma.

HOW TO CITE THIS ARTICLE: Rajachidambaram K, Sowmya TK. Modified triple assessment in breast lumps. J. Evolution Med. Dent. Sci. 2016;5(36):2123-2130, DOI: 10.14260/jemds/2016/497

\section{INTRODUCTION}

The study is conducted with the objective of assessing the combined and individual reliability of the Modified Triple Test in making a pre-procedural diagnosis of palpable breast lumps.

\section{The Components of the Modified Triple Tests are}

- Clinical Examination (C/E).

- Breast Ultrasonogram (USG).

- Fine Needle Aspiration Cytology (FNAC).

Financial or Other, Competing Interest: None.

Submission 10-03-2016, Peer Review 23-03-2016,

Acceptance 25-03-2016, Published 04-05-2016.

Corresponding Author:

Dr. Karunamoorthy Rajachidambaram,

93G/5A Chidambaram Nagar,

Near New Bus Stand,

Perambalur-621212.

E-mail: drkrajachidambaram@gmail.com

DOI: 10.14260/jemds/2016/497

\section{MATERIALS AND METHODS}

A prospective cross sectional study of 100 female patients attending the outpatient department at the Department of General Surgery, Chennai Medical College and Hospital, Irungalur, Trichy, with the complaint of a palpable lump/lumps in the breast was undertaken.

Male patients and female patients with advanced Breast Cancer that makes diagnosis obvious were excluded from the study $(\mathrm{n}=32)$.

Female patients $\mathrm{C} / \mathrm{o}$ breast lump-clinically palpable as a localized lesion differing from the surrounding breast tissue.

Each patient was put through the Modified Triple Test. On the basis of a systematic clinical examination, the lumps were grouped as - malignant, benign of inconclusive.

Ultrasound of the breast was performed by a senior Radiologist using an Esaote Biomedica AU3 Partner ultrasound machine with a $10 \mathrm{MHz}$ probe. The lesions were classified as Malignant, Benign or Inconclusive based on the following features. 
a. Malignant-III defined, heterogeneous mass with sharp angulations; presence of microcalcifications.

b. Benign lesions were either cystic or solid.

Cysts - Round, oval, anechoic, well defined with through and through transmission in simple cysts. Abscesses show lowlevel internal echoes.

\begin{tabular}{|c|c|c|}
\hline $\begin{array}{c}\text { Solid: } 1 . \\
\text { Fibroaden } \\
\text { oma }\end{array}$ & - & $\begin{array}{c}\text { Round, oval. } \\
\text { Bi/Trilobulated. }\end{array}$ \\
\hline $\begin{array}{c}\text { Well defined with pseudocapsule } \\
\text { Homogenous internal echoes. }\end{array}$ \\
$\begin{array}{c}\text { Fibroaden } \\
\text { osis }\end{array}$ & - & $\begin{array}{c}\text { Generalized increase in the fibroglandular } \\
\text { elements of breast. }\end{array}$ \\
$\begin{array}{c}\text { Hyperechoic shadows with cystic areas. } \\
\text { No distortion of breast architecture. }\end{array}$ \\
\hline
\end{tabular}

Ultrasound examination also included the contralateral breast, axillae and internal mammary lymph nodes. For deeply seated lesions sono-guidance was utilized to aspirate cysts and to take biopsies.

After this, FNAC/CNB was performed by the attending surgeon and sent for cytological/histopathological examination.

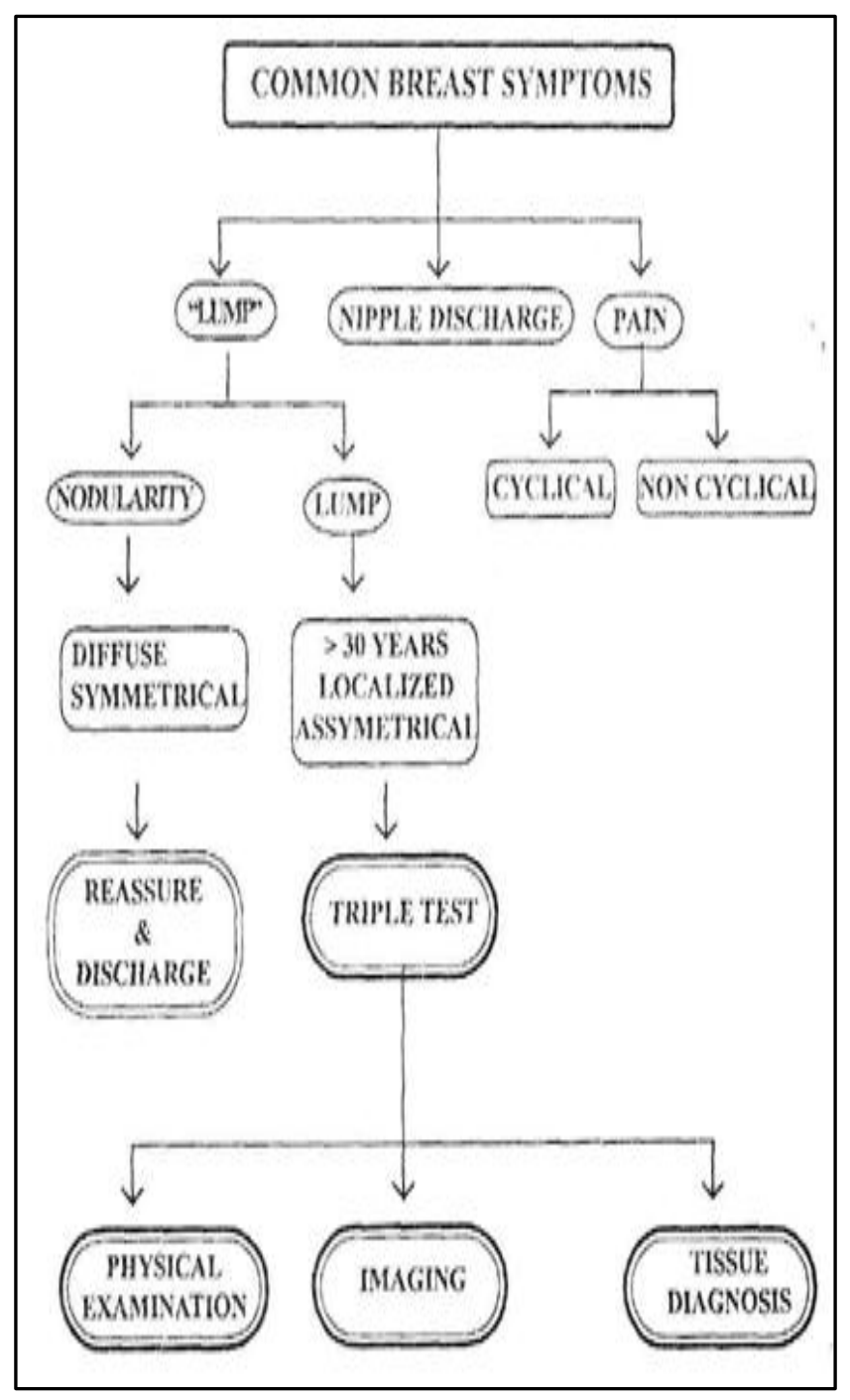

Chart 1: Flow Chart showing Diagnostic Protocol for Patients with Breast Complaints

\begin{tabular}{|c|c|}
\hline $\begin{array}{c}|c| \\
\text { a. Insufficient } \\
\text { material: }\end{array}$ & $\begin{array}{c}\text { Cell content in the aspirate too poor } \\
\text { for cytological assessment. }\end{array}$ \\
\hline b. Benign cells: & $\begin{array}{c}\text { Sufficient material with benign cells } \\
\text { indicating Fibroadenoma of } \\
\text { Fibrocystic disease. }\end{array}$ \\
\hline c. Atypical cells: & $\begin{array}{c}\text { Slight atypia; interpreted as benign } \\
\text { lesion. }\end{array}$ \\
\hline d. Suspicious: & $\begin{array}{c}\text { Malignancy-suspect cells; not } \\
\text { interpretable as carcinoma with } \\
\text { certainty. }\end{array}$ \\
\hline e. Carcinoma: & Cells indicative of malignance. \\
\hline
\end{tabular}

Results were interpreted as follows:

A- Repeat FNAC.

$\mathrm{B}, \mathrm{C}$-Benign.

D-Inconclusive.

E-Malignant.

The results of the modified triple test were then analysed individually and as a combination. Any component indicating a malignant report was taken as malignancy. Inconclusive reports were subject to excision biopsy on an inpatient basis. Patients with malignancy were treated with definitive surgery. The post procedural histopathological reports were compared to the results of the Modified Triple Test.

\section{DISCUSSION}

Breast lumps are an enormous source of anxiety to patients and a stratified approach has to be adapted to properly (Chart 1) Evaluate and treat them. Though benign breast diseases are more common, there is a preoccupation with malignancy [Undue but understandable] amongst the patients and physicians alike.

- The ultimate diagnosis and treatment of a patient with a dominant breast mass rests with the clinician. A dominant breast mass is defined as a solid or cystic lump that persists throughout the menstrual cycle.

- The preop assessment of a breast mass begins with a thorough history and systematic physical examination. However, it is generally accepted that this alone can be inadequate for an accurate diagnosis. The breast is naturally multinodular and hence the difficulty in appreciating small nodules amidst the normal lumpiness is apparent. Apart from this is the varied expertise of the examiner in breast palpation. Thus imaging of the breast using various physical imaging modalities is important.(3)

- The earliest recorded case of breast imaging is that of Salomon, a German pathologist, who in 1913 reported the use of the recently developed X-ray to visualize breast structure in amputated breasts. He demonstrated the irregular mass density and microcalcification, which are still in use as the most important benchmarks to identify possible breast malignancy. Even today mammography remains the method of choice for detecting the occult.(4) 


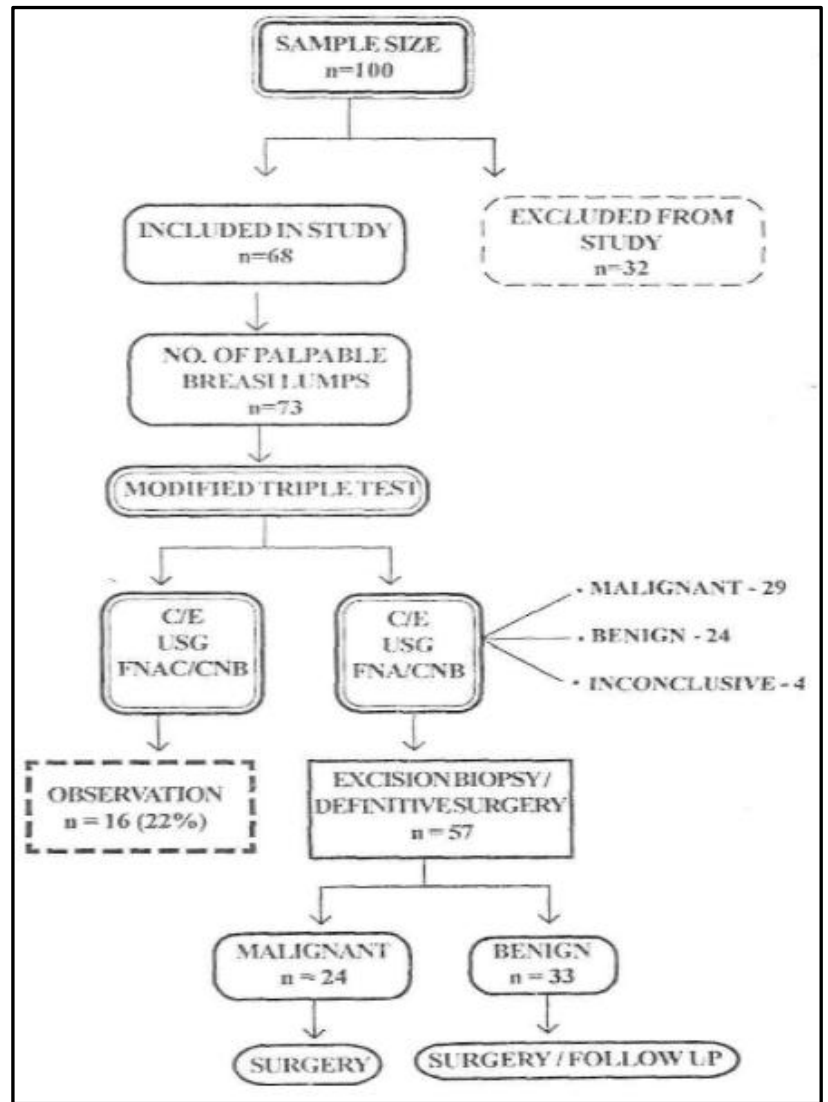

Chart 3: Flow Chart Depicting the Study Protocol

Non-palpable lesion remains the standard for imaging of breast against which other modalities advocated now are measured.

Other Imaging Modalities have now been Introduced for

- Visualizing lesion missed by mammography.

- To replace mammography with another efficient, more economic device that would also be used by nonradiologists.

The diagnostic utility of ultrasonogram was documented in 1950s, but it was only with the development of "Grey scaling" by Korsakoff and associates in Sweden years later that better tissue representation was obtained. Recent technical advances in ultrasonography have expanded the potential utility of this modality in the evaluation of breast lesions far beyond distinguishing solid abnormalities from cystic ones.

Tissue diagnosis remains the most reliable confirmatory tool for breast lumps.(5) In 1912, Ward used Fine Needle Aspiration (FNAC) Cytology to examine lymph nodes for lymphoma. Eventually, Martin and Ellis at New York attempted the procedure on patients with breast lumps in 1926. Cytological interpretation requires skill particularly in view of cell types and pathologies encountered, but high levels of accuracy can be obtained with experience.

\section{Clinical Examination}

A palpable breast mass may be identified when it becomes sufficiently large to be differentiated from surrounding breast tissue, physically by an examiner - usually the patient or the physician; or is perceived on an imaging examination. Determining by physical examination whether a mass is present can be difficult as all breasts are variable in the combination of glandular tissue, fibrosis and fat. True masses are generally asymmetric in relation to the other breast; distinct from the surrounding tissue and three-dimensional.

The underlying cause of complaints about the breast proves to be benign in the overwhelming majority of cases. Breast symptoms, however, induce such a great anxiety in the patient that malignancy needs to be excluded as speedily as possible.

The first steps in this are the classic ones of history and physical examination.

In physical examination of patients with a breast complaint - seclusion, warmth and privacy are particularly important in the examination of the breast. This avoids discomfort and embarrassment to the patient. Good lighting enables detection of minor abnormalities. The patient sits stripped to the waist. Attention is paid to,

\section{General Appearance}

Nourishment, colour, mucous membranes, palms. Inspection

1. Arms by side.

2. Arms elevated.

Looking for Symmetry of nipples and breasts.

\section{Symmetry of Nipples and Breasts.}

a. Nipple abnormalities.

b. Vascularity.

c. Indrawing and prominence of skin.

d. Tethering.

e. Peau D'orange.

f. Skin nodule.

g. Ulceration.

\section{Palpation}

1. Supraclavicular fossae.

2. Breasts.

a) Lightly.

b) Deeply systematically from the areola concentrically outwards including the axillary tail.

3. Axillae.

a. Taking the weight off the patient's forearm on the examiner's.

b. Both axillae simultaneously from behind the patient.

3. Abdomen for ascites, hepatomegaly or abnormal masses.

\section{Particularly Valuable in Practice are}

1. Inspection with arms firstly dependent, then elevated.

2. Initial light touch over the breasts prior to systematic deeper palpation in concentric circles, working outwards.

3. Simultaneous examination of the axillae performed from behind the patient.

Atypical cancer may be firm and have indistinct borders and attachments to the skin or deep fascia with dimpling or nipple retraction. Benign lesions typically have discrete borders, well-defined margins and are mobile. Cysts can be differentiated from solid lesions by palpation.

Rosner et al reported that physical examination correctly identifies only $58 \%$ of 66 patients with cysts. Significant discordance among experienced examiners may occur. In one study, surgeons performed physical examination 
independently and agreed on the need for biopsy in only $73 \%$ of 15 masses subsequently proved malignant. (Boyd et al).

Somers et al studied certain palpable abnormalities defined as areas of thickening, prominence of tenderness without an associated dominant mass on physical examination; no suspicious mammographic lesion and rubbery, firm, cystic soft mass, needle sensation by FNAC. The incidence of malignancy in these 'suspicious' groups was less than $1 \%(1 / 106)$, leading to the conclusion that this subset of patients with palpable abnormalities did not require surgical biopsy.

Nevertheless, the physical findings of benign disease and malignancy in its earliest stages may overlap and without the use of 1- "NA and/or breast imaging, some palpable malignant lesions may be followed up inappropriately, leading to serious consequences for both the patient and the physician."

Although some masses exhibit distinct physical findings, an imaging evaluation is required in almost all cases to characterize the palpable lesion, search for ipsilateral multifocal or multicentric carcinoma and screen the contralateral breast. A negative imaging evaluation, however, should never overrule a strongly suspicious finding on physical examination or vice versa.

\section{Ultrasound of The Breast}

Although diagnostic ultrasound equipment has been available since the 1950s, it is only in relatively recent years that the widespread use of this technique has been accepted by radiologists and then by surgeons. A lot of this has related to difficulties with earlier machines.

1. Even with all the advances, it must be stated and emphasized that the use of USG equipment in very operator dependant and interpretation of the images requires a large amount of practical training. Skilled interpreters of ultrasonic images do however follow 3 golden rules - never make an interpretation on a single image, superimpose the ultrasonic images mentally to formulate a 3 dimensional image of the scanned tissues and to ensure that the displayed feature is consistent with the 3D image.

2. Because a feature is displayed, it is not necessarily real always rule out artifacts.

3. Because a feature is not displayed, it is not necessarily not there.

The original use of USG was to determine whether a breast mass was a cyst or solid lesion. Advances in technology and refinements in interpretative criteria have expanded the role of USG in characterizing masses as having benign, malignant or equivocal features.

\section{Breast Ultrasound Technique}

- Confirm the location of the mass noted on physical examination: a diagram from the referring physicians to demonstrate the lesions position.

- A high-resolution small parts transducer 7.5-10 $\mathrm{MHz}$ is used.

- Evaluate the Region of Interest (ROI) to assess whether the clinical abnormality is corresponding to the ultrasound findings.

- Patient positioning: The patient is positioned in an oblique manner with a pillow placed under the shoulder of the breast to be examined.
The degree of obliquity is determined by the position of the breast-aiming to have the breast spread evenly over the chest wall with the nipple pointing to the ceiling. The arm should be elevated over the patient's head to facilitate even distribution of the breast tissue, but should not be so elevated that the breast is retracted superiorly. A little care exercised in positioning the patients makes the USG localization of the lesion less of a problem.

a. Lumps felt better in the upright position may be scanned in that position.

b. Fluid levels in cystic masses may be confirmed by changing to upright/decubitus position.

- Region of interest is trapped with the examining finger and the transducer is placed directly over the abnormality.

- Examine in overlapping radial/antiradial planes-to determine relation of lesion to ducts and avoid errors as mistaking fat islands for solid masses.

- The entire periphery of the lesion must be evaluated in multiple planes through 180-degree arc to determine the nature of margins, its shape and appearance of surrounding tissue.

- Compression of tissue with the transducer is helpful in spreading apart breast tissues, flattening islands of fatty tissue and eliminating art factual shadowing.

- The rest of the breast tissue is systematically imaged from periphery to the nipple.

- The retroareolar area can be evaluated with the transducer angled into the area in multiple planes.

\section{Labelling of Lesions}

- The lesion is labelled on a clock face.

- Its distance from nipple is given in centimeters.

- The greatest diameter should be measured.

- The height (AP diameter) is determined to obtain a height/width ratio.

When the breast masses meet all of the diagnostic criteria for cysts, the USG accuracy approaches $100 \%$.

\section{The Criteria Include}

1. Round, oval lobulated shape.

2. Anechoic.

3. Well-defined posterior border.

4. Increased through and through transmission.

5. No alteration of surrounding parenchyma.

Unfortunately, not all cysts display these criteria. The resolution of USG for cystic lesions is up to $5 \mathrm{~mm}$ with $100 \%$ accuracy.

The presence of internal echoes is the most common diagnostic difficulty in cyst/solid differentiation. Cysts have internal echoes due to

- Presence of cholesterol or calcium.

- Haemorrhage.

- Infection. 


\begin{tabular}{|c|c|}
\hline \multicolumn{2}{|c|}{ FOLLOW UP OF CYSTIC LESIONS } \\
\hline \multicolumn{2}{|l|}{ Chart-(2) } \\
\hline \multirow{15}{*}{ SIMPLE CYST } & \\
\hline & Confirm benign nature and observe \\
\hline & $\downarrow$ \\
\hline & Follow-up Usg at 4-6 months \\
\hline & "No malignant or indeterminate features \\
\hline & $\downarrow$ \\
\hline & Observe \\
\hline & COMPLEX CYST \\
\hline & Large complex/ indeterminate cysts \\
\hline & $\downarrow$ \\
\hline & Usg guided aspiration/ presence intracystic mass \\
\hline & $\downarrow$ \\
\hline & Bloody or turbid aspirate \\
\hline & $\downarrow$ \\
\hline & Usg guided biopsy / cytological evaluation \\
\hline
\end{tabular}

With the aid of the above criteria USG can come to a reliable diagnosis of breast lumps depending upon the size of the lesions. The minimum size of cystic lesions picked up by USG are $2-3 \mathrm{~mm}$. Solid lesions $>0.5 \mathrm{~cm}$ are usually categorized with accuracy, $80 \%$ of solid lesions $>2 \mathrm{cms}$ and $20 \%$ of lumps $>1-2 \mathrm{cms}$ and $5 \%$ of lumps $<1 \mathrm{~cm}$ is the diagnostic accuracy of USG.

\section{Indications for Breast Ultrasound}

From the above discussion, we can summarize the now standardized indications for Breast Ultrasound as follows:

1. Evaluation of a palpable lump or mammographic abnormality.

2. To confirm the existence of a lesion and its nature.

3. Single imaging modality in your patients or in pregnant or lactating patients who present with symptoms.

4. To differentiate solid from cystic lesions.

5. For pathological examination of indeterminate lesionsguided FNAC/CNB can be carried out.

6. Pre-operative localization of lesions with needle placements, documentation of lesion removal by USG of biopsy specimen.

7. Followup of surgically altered breast by tracing it through the breast and subcutaneous layer to the biopsy scar on skin as well as for guidance for FNAC/CNB.

8. Followup after augmentation mammoplasty to detect extracapsular rupture/contour abnormalities of the prosthesis.

9. Followup of probably benign lesions that have not been biopsied.

10. Adjunctive to mammography as a screening tool for carcinoma breast.

\section{Advantages of USG Over Breast Mammography}

1. No risk of radiation and its inherent consequences.

2. Can qualify a lesion - as size, shape, echogenicity and relation to surrounding tissues as against a mammographic report of a 'Density,' which is less specific.
3. Sonographically guided biopsies are more accurate than stereotactic biopsies as the needle can be visualized in real time throughout the entire procedure. This adds confidence that the biopsy sample was obtained from the lesion.

4. Mammographic positioning for pre-operative localization of the masses is cumbersome and time consuming and less accurate. Hence, USG is the modality of choice for guidance.

5. Surgically altered breast has confusing findings and is non-informative on mammography.

6. Palpable lumps following extracapsular rupture of prosthesis may be impossible to image by mammography.

7. Long-term follow-up of benign nodules not excised is associated with risk of radiation on mammography and hence best performed by USG.

\section{Limitations of Breast Ultrasound.(6)}

Breast ultrasound usage is avoided in certain situations where no efficacy has been documented.

1. Routine evaluation of postoperative breast.

2. Cancer Screening - as USG cannot detect all the nonpalpable cancers that are also missed on mammography.

3. Cannot detect microcalcification well; small solid lesions in fatty or mixed breast tissue are not Sonographically visible.

4. High false negative rate for non-palpable cancers, (23\%) which arc smaller, clinically occult.

5. Substantial false positive rate - sonogram may pick up 'lesions,' which are rarely clinically significant.

6. Unreliable in lesions $<\mathrm{l} \mathrm{cm}$.

7. Less accurate in dense breasts.

These data suggest that breast ultrasound can be useful both as a single imaging modality and as an adjunct of mammography in evaluation of patients with breast lumps. In addition, ultrasound facilitates preoperative needle biopsy of non-palpable abnormalities permitting timely and cost effective patient care.

\section{Fine Needle Aspiration Cytology}

The advent of cytology and availability of experienced cytologists has diminished the diagnostic role of excision biopsy, especially with regard to breast lumps.

FNAC can play a significant role in the early diagnosis of breast lumps to rule out malignancy, as an attractive alternative to open biopsy.(7) It is our responsibility to further the integrity of this important procedure by understanding the merits and pitfalls of breasts FNAC and adhering to the defined guidelines.

\section{Requirements}

1. Spirit swab to clean the skin.

2. Disposable $10 \mathrm{~mL}$ or $20 \mathrm{~mL}$ syringe with fine needle 22G/23G.

3. A number of $76 \mathrm{~mm} \times 26 \mathrm{~mm}$ microscopic slides.

4. Fixatives like cytofix solution, which is a commercial preparation containing absolute alcohol as its main constituent.

5. Transport box for prepared slides.

6. Complete lab request form giving patient's particulars. 


\section{Procedure}

The procedure is usually performed without anaesthesia. Very rarely local anaesthesia is used. Local anaesthesia is generally not necessary, because it is painful and may obscure the mass.

1. The skin over the lump is wiped with antiseptic solution and the lump is fixed between the fingers and the thumb and held steadily for needling. Then needle is guided through the skin into the lesion.

2. Once the needle is felt to enter the lesion, the plunger is retracted to create vacuum. Should the lesion prove to be cystic, the fluid should be aspirated in its entirety and expressed into a universal container and sent for cytological examination.

3. If the lump is found to be solid, the needle in gently moved back and forth into the substance of the tumour three or four times and is inserted into a different part of the tumour each time to dislodge the cells from the tumour, so that the aspirate will contain the sufficient material for cytological studies.

4. Throughout the technique, a negative pressure must be sustained in the syringe. Only after the tumour has been repeatedly probed, should suction be released ant the pressure in the syringe allowed to return gradually to atmospheric pressure and the needle is withdrawal from the breast. The pressure in the syringe must be adjusted in a way, so that the aspirated cells are retained in the lumen of the needle, sustained suction as the needle is withdrawn result in the cells being withdrawn into the barrel of the syringe rendering them inaccessible for processing.

\section{Advantages of FNAC}

1. Does not require anaesthesia.

2. Tolerated by patients as an OP procedure.

3. No specialized equipment required.

4. No damage to breast tissue that may occur with open biopsy.

5. Though small haematomas may be encountered, neither haemorrhage nor sepsis is noted.

6. Remote chances of tumour seeding along needle tract.

7. Lymphatic/vascular dissemination of tumour is virtually unknown.

8. Can easily diagnose cysts/abscesses and treat them.

9. Eliminated need for open biopsy when a diagnosis of carcinoma is made, that is the incidence of false positive in malignancy is almost nil.

10. Can be easily repeated.

Limitations of FNAC. $(8)$

1. Cannot qualify the type of malignancy.

2. False negative reporting when.

a. Small tumours $<1 \mathrm{~cm}$.

b. Sclerotic lesions.

c. Deep seated tumours.

d. Large/pendulous breasts.

e. Lesions beyond the length of the needle.

\section{Data Analysis}

Of the patients randomly referred for the study $(n=100)$, patients not fitting the inclusion criteria were excluded $(\mathrm{n}=32)$. Thus 68 patients with 73 breast lumps were inducted into the study.
The MTT obviated excision biopsy in 16 patients (22\%) and this is the potential advantage of this test. Thus the final study group ( $\left.\mathrm{n}^{\wedge} 57\right)$ underwent the MTT followed by excision biopsy, the results of which were available for comparison.

The average age of women in this study was $41.84+9.1$. The mean shifting to 47 years in patients with malignancy, the youngest patient was 30 years and the oldest was 65 years. This conforms with the suitable age for subjecting patients to screening procedure followed worldwide (i.e.) above 40 years.

Benign lesions were more common amongst premenopausal women ( $\mathrm{n}=33)$; though malignancy could not be excluded in this group $(n=24)$. However, all the lesions detected in premenopausal $(n=5)$ postmenopausal on excision biopsy, the 57 lumps were confirmed histopathologically as either malignant $(n=24)$ and benign $(n=33)$.

The pathological reports were;

\begin{tabular}{|lll|}
\hline The pathological reports were; & & \\
Total no. of malignancies & $=$ & 24 \\
Intra Ductal Carcinoma & $=$ & 1 \\
Lobular Carcinoma & $=$ & 1 \\
Medullary Carcinoma & $=$ & \\
Carcino Sarcoma & & \\
Malignant cystosarcoma & $=$ & 1 \\
Phylloides & $=$ & 33 \\
Total no. of Benign lesions & $=$ & 14 \\
Fibroadenoma & $=$ & 10 \\
Fibrocystic Disease & $=$ & 6 \\
Breast Abscess & & \\
Benign cystosarcoma & $=$ & 3 \\
Phylloides &
\end{tabular}

The associations between each component of MTT and the combined MTT with the biopsy report were subjected to computer-generated analysis.

Clinical examination finding of a hard, irregular lump was more likely to be malignant, while a soft or firm mass with regular surface suggested benign lesions (]$\left.^{\wedge}>0.001\right)$. Benign lesions most often confused with malignancy were Benign Cystosarcoma Phyllodes and Fibrocystic disease (Table 3).

\begin{tabular}{|c|c|c|}
\hline Consistency & Malignancy & Benign \\
\hline Hard & 18 & 3 \\
\hline Firm & 5 & 30 \\
\hline Soft & 0 & 1 \\
\hline Surface & 18 & 6 \\
\hline Irregular & 6 & 27 \\
\hline Regular & Table 3 \\
\hline \multicolumn{3}{|c|}{} \\
\hline
\end{tabular}

$\mathrm{P}<0.001$

The initial indications of USG in differentiating a solid from cystic lesions may be non-beneficial in coming to a correct diagnosis. Our study shows no association between the character of the lesion and diagnosis $(\mathrm{P}>0.05)$ (Table 4$)$.

\begin{tabular}{|c|c|c|}
\hline Consistency & Malignancy & Benign \\
\hline Cystic & 2 & 6 \\
\hline Solid & 22 & 28 \\
\hline \multicolumn{2}{|c|}{ Table 4: Ultrasound Findings and HPE } \\
\hline
\end{tabular}

A regular, well defined, hyperechoic lesion was usually benign. An irregular, ill-defined mixed echogenic mass 
indicated malignancy. Hypoechoic lesions were not characteristic of either $\left(\mathrm{P}^{\wedge} 0.05\right)$. Echogenicity could not thus be used as a singular feature to rule out malignancy except when they were hyperechoic (Table 5)

\begin{tabular}{|c|c|c|}
\hline Echogenicity & Malignancy & Benign \\
\hline Mixed & 10 & 6 \\
\hline Hypoechoic & 14 & 23 \\
\hline Hyperechoic & 0 & 4 \\
\hline \multicolumn{2}{|c|}{ Table 5: Echogenicity of Lesions and HPE } \\
\hline
\end{tabular}

Ultrasound detected Axillary nodes in all patients $(n=12)$ found to be clinically node positive; however, it could not distinguish whether the node had malignant infiltration or not.

Ultrasound guided FNAC/CNB was done in 6 cases; 2 of which were cystic lesions with a residual mass on aspiration of the cysts. Both turned out to be malignancies missed on routine FNAC.

Amongst the individual tests, clinical examination was more likely to miss a malignancy (Sensitivity 75\%), as against ultrasound (Sensitivity 92\%) or FNAC/CNB (Sensitivity 100\%). FNAC/CNB correctly identified malignancy in all 24 cases, while ultrasound misinterpreted 1 case as malignant (A case of Benign Cystosarcoma Phyllodes) with specificities of $100 \%$ and $85 \%$ respectively.

The MTT was $85 \%$ specific with malignant lesions. But 5 cases were misdiagnosed as malignancies and turned out in 3 cases to be Fibrocystic Disease and 2 cases were benign Cystosarcoma Phyllodes - both benign lesions. Inconclusive results $(n=4)$ on MTT were also confirmed to be benign lesions. Thus, MTT though had false positives with respect to malignancy but no false negatives

\begin{tabular}{|c|c|c|}
\hline \multirow{2}{*}{ Ultrasonogram } & \multicolumn{2}{|c|}{ HPE } \\
\cline { 2 - 3 } & Malignancy & Benign \\
\hline Malignant & 22 & 3 \\
\hline Benign & 1 & 28 \\
\hline Inconclusive & 1 & 2 \\
\hline \multicolumn{2}{|c|}{ Table 6: Association Between Ultrasonogram and HPE } \\
\hline
\end{tabular}

\begin{tabular}{|c|c|c|c|c|}
\hline & C/E & USG & $\begin{array}{c}\text { FNAC } \\
\text { /CNB }\end{array}$ & MTT \\
\hline Sensitivity & $\begin{array}{c}75 \% \\
(53-80 \%)\end{array}$ & $\begin{array}{c}92 \% \\
(72-99 \%)\end{array}$ & $\begin{array}{c}100 \% \\
(83-100 \%)\end{array}$ & $\begin{array}{c}100 \% \\
(83-100 \%)\end{array}$ \\
\hline Specificity & $\begin{array}{c}97 \% \\
(82-00 \%)\end{array}$ & $\begin{array}{c}85 \% \\
(67-94 \%)\end{array}$ & $\begin{array}{c}100 \% \\
(87-100 \%)\end{array}$ & $\begin{array}{c}85 \% \\
(67-94 \%)\end{array}$ \\
\hline $\begin{array}{c}\text { Positive } \\
\text { Predictive } \\
\text { Value }\end{array}$ & $\begin{array}{c}95 \% \\
(70-99 \%)\end{array}$ & $\begin{array}{c}81 \% \\
(61-3 \%)\end{array}$ & $\begin{array}{c}100 \% \\
(83-100 \%)\end{array}$ & $\begin{array}{c}83 \% \\
(64-93 \%)\end{array}$ \\
\hline $\begin{array}{c}\text { Negative } \\
\text { Predictive } \\
\text { Value }\end{array}$ & $\begin{array}{c}84 \% \\
(64-90 \%)\end{array}$ & $\begin{array}{c}93 \% \\
(76-9 \%)\end{array}$ & $\begin{array}{c}100 \% \\
(87-100 \%)\end{array}$ & $\begin{array}{c}100 \% \\
(85-100 \%)\end{array}$ \\
\hline 'P' Value & $<0.001$ & $<0.001$ & $<0.001$ & $<0.001$ \\
\hline \multicolumn{5}{|c|}{ Table 7: Statistical Analysis of the Study } \\
\hline \multicolumn{5}{|c|}{}
\end{tabular}

FNA/CNB as a single test was a superior diagnostic test than the other two tests, but only when complemented by them could the lesion be characterized in all dimensions for the chosen interventional procedure.
When an inconclusive was reported, the likelihood of malignancy increases in ascending order from FNAC/CNB, USG to $C / E$ ( $n=0, n=l, n=5$ respectively). All 4 cases deemed inconclusive after MTT were later diagnosed as fibrocystic disease.

\section{CONCLUSION}

Detection and management of a breast mass requires an optimal environment for interpretation, relevant use of clinical information, technically excellent imaging procedures, proper interpretation of finding and pertinent recommendations. Our results show that the diagnostic accuracy of combined physical examination breast USG and FNAC/CNB is comparable to that of histological examination.

A fine collaboration between experienced radiologists, cytologist and the clinician is required. Ultrasound when replacing mammography serves as effective, an imaging modality in palpable breast lumps and is more comprehensive.

Ultrasound breast aids biopsy techniques by guidance to the representative area than increasing yield. CNB is a suitable alternative when FNAC is inconclusive and may offer additional information. $(9)$

Thus, the use of MTT to complement findings in differential diagnosis of a lesion in a symptomatic women seeking medical care deserves acceptance and further evaluation.(10) This may lead to less delay in treatment when malignancy is suspected and to avoidance of surgical exploration when a benign nature of lesion is suspected.

\section{REFERENCES}

1. Ahmed I, Nazir R, Chaudary MY, et al. Triple assessment of breast lump. J Coll Physicians Surg Pak 2007;17(9):535-8.

2. Zhi H, Ou B, Luo BM, et al. Comparison of ultrasound elastography, mammography, and sonography in the diagnosis of solid breast lesions. JUM 2007;26(6):80715.

3. Drew PJ, Chatterjee S, Turnbull LW, et al. Dynamic contrast enhanced magnetic resonance imaging of the breast is superior to triple assessment for the preoperative detection of multifocal breast cancer. Ann Surg Oncol 1999;6(6):599-603.

4. Yeh E, Slanetz P, Kopans DB, et al. Prospective comparison of mammography, sonography, and MRI in patients undergoing neoadjuvant chemotherapy for palpable breast cancer. American Journal of Roentgenology 2005;184.

5. Robinson IA, McKee G, Nicholson A, et al. Prognostic value of cytological grading of fine-needle aspirates from breast carcinomas. The Lancet 1994; 343 (8903) : 947-9.

6. Stavros AT. Breast ultrasound. Lippincott Williams \& Wilkins; 2004;pp 1030.

7. Dennison G, Anand R, Makar SH, et al. A prospective study of the use of fine-needle aspiration cytology and core biopsy in the diagnosis of breast cancer. The Breast Journal 2003;9(6):491-3.

8. Zagorianakou P, Fiaccavento S, Zagorianakou N, et al. FNAC: its role, limitations and perspective in the preoperative diagnosis of breast cancer. Eur J Gynaecol Oncol 2004;26(2):143-9. 
9. Tiwari M. Role of fine needle aspiration cytology in diagnosis of breast lumps. Kathmandu Univ Med J 2007;5(2):215-7.
10. Tan SM, Behranwala KA, Trott PA, et al. A retrospective study comparing the individual modalities of triple assessment in the pre-operative diagnosis of invasive lobular breast carcinoma. European Journal of Surgical Oncology 2002;28(3):203-8 